\title{
On the Improvement of Wind Power Predictions Based on Terrain Characteristics and Measurements of the Annual Energy Production
}

\author{
Jonathan Dorval', Christian Masson', Yves Gagnon² \\ ${ }^{1}$ Department of Mechanical Engineering, École de technologie supérieure, Montreal, Canada \\ ${ }^{2}$ Department of Sciences, Université de Moncton, Edmundston, Canada \\ Email: jonathan.dorval@gmail.com,Christian.masson@etsmtl.ca,yves.gagnon@umoncton.ca
}

How to cite this paper: Dorval, J., Masson, C. and Gagnon, Y. (2017) On the Improvement of Wind Power Predictions Based on Terrain Characteristics and Measurements of the Annual Energy Production. Journal of Flow Control, Measurement \& Visualization, 5, 1-20.

https://doi.org/10.4236/jfcmv.2017.51001

Received: November 17, 2016

Accepted: February 6, 2017

Published: February 9, 2017

Copyright $\odot 2017$ by authors and Scientific Research Publishing Inc. This work is licensed under the Creative Commons Attribution International License (CC BY 4.0).

http://creativecommons.org/licenses/by/4.0/

\begin{abstract}
The assessment of the production capacity of wind farms is a crucial step in wind farm design processes, where a poor assessment can cause significant economic losses. Data from Canadian wind farms benefiting from national production incentive programs show that wind farms are typically characterized by an overestimation of the production capacity. In this context, a study has been done to provide insight on the origin of the discrepancies between the energy production estimates and the measured energy generation, and to develop a method to reduce these discrepancies. To this end, the WAsP and MS-Micro models have been studied. Besides the wind speed measurements, topography indices have been developed to identify the influence of the various characteristics of the site on the error in the annual energy production $(A E P)$. In addition, roughness classes have been created, including a reference roughness and a roughness complexity. The indices have also allowed establishing correlations and developing equations to evaluate the error based on the site characteristics and the positions of wind turbines on the measured annual energy production. An average reduction of up to $83 \%$ on the $A E P$ errors was obtained when the methodology was applied to five wind farms in Canada.
\end{abstract}

\section{Keywords}

Wind Energy, Wind Farm Assessment, WAsP, MS-Micro, Roughness Classes, Roughness Complexity

\section{Introduction}

Similar to the rest of the world, the wind power industry in Canada has expe- 
rienced significant growth over the last decade. The total Canadian wind capacity surpassed the $1000 \mathrm{MW}$ mark in 2006 and it reached more than 11,000 MW in 2015 [1]. In order to assist in the growth of wind energy, the Government of Canada took several initiatives to accelerate the development of renewable energy in the country. One of the government's initiatives has been in the form of wind power production incentive programs, notably the Wind Power Production Incentive program (WPPI) and the EcoEnergy program (EcoERP) [2]. These programs subsidize wind energy projects based on their estimated annual energy production.

A study from Natural Resources Canada on the annual energy production $(A E P)$ of 59 projects funded by the WPPI and EcoERP programs [3] has shown that, in 2011, while a capacity factor of $34.2 \%$ was expected for the wind farms benefitting from the programs, the effective capacity factor was only $29.9 \%$. This difference means an underperformance of about $12.5 \%$ and represents significant losses in economic terms. This behavior of underperformance of wind farms has been observed year after year.

Besides the daily and seasonal variations, the wind resource on a specific site is influenced by the physical characteristics of the terrain. Carvalho et al. [4] showed that these characteristics are significantly enhanced when dealing with a complex terrain, where the wind predictions are more difficult to achieve. Thus, the estimation of the wind resource, and more specifically the annual energy production $(A E P)$ using the wind speed distribution of the IEC 61400-12-1 standard, might lead to significant uncertainties [5].

Studies have been published in the literature to assess the feasibility of wind energy in various conditions. For example, Rehman et al. [6] [7] presented wind resource assessments, along with the design and the economic assessment of a 20 MW wind power plant, using $2 \mathrm{MW}$ turbines, located in the Eastern region of Saudi Arabia. Specific to wind farms, Touani et al. [8] developed of a Wind to Power Model for wind farm power production forecasting, where wind farm power curves are used to convert the predicted wind speeds to predicted power productions of wind farms. In their work, they have however not considered the site characteristics of the wind farms.

Kwon [9] proposed a methodology to better assess the $A E P$ of wind farms. While making some simplifying assumptions, this methodology introduces a new approach for long-term corrections, the vertical extrapolation of the wind distribution and the power performance of the wind turbines by taking into account the uncertainties. However, the effects of the terrain on the $A E P$ are not considered.

It is known that the land cover (roughness) and terrain height variations (orography) influence the wind. When these effects are not well interpreted, the horizontal and vertical extrapolation of the wind speed can have significant uncertainties, thus providing erroneous $A E P$ estimates.

The present study aims to better understand the effect of orography and roughness on the production capacity of wind farms and to develop a metho- 
dology to reduce the gap between the energy production estimates and the actual measured energy generation, and to develop a method to reduce these discrepancies.

The models studied are WAsP [10] and MS-Micro [11], which are linear models based on the analysis of the theory of flow over hills by Jackson and Hunt [12]. The simplifications of the Navier-Stoke equations in the models generate uncertainties, notably when flow separation occurs.

Bowen and Mortensen [13] [14] developed a methodology to evaluate the accuracy of the WAsP model in complex terrains. It has been shown [13] [14] [15] that a relationship, called the ruggedness index $(\Delta R I X)$, exists between the mean wind speed errors and a flow separation indicator.

Mortensen et al. [16] investigated the optimum configuration of the parameters for the $R I X$ calculation and showed that there is also a relationship between the $A E P$ errors and $\triangle R I X$. A coefficient of determination $\left(R^{2}\right)$ of $97.7 \%$ was obtained between the $\triangle R I X$ and the $A E P$ errors on five sites located in rugged mountainous areas of northern Portugal.

Berge et al. [17] also obtained good correlations between the $\triangle R I X$ and the mean wind speed errors on five mountainous sites in Norway by using WAsP. Moreover, they investigated the relationship between the wind speed errors and the differences in heights and horizontal distances. No correlation was visible between the mean wind speed errors and the horizontal distances and a weak correlation was observed between wind speed errors and the difference in heights.

Feng et al. [18] validated the ruggedness index methodology based on energy production with data from an existing wind farm. The energy production corrected was more accurate; however, $A E P$ errors up to $9.4 \%$ were still observed. For their part, Jimenez et al. [19] investigated WAsP on two offshore, one onshore and three island sites located in northern Germany. Four sites correlated well with each other, with mean wind speed errors up to $2 \%$, while the two other sites gave significant mean wind speed errors.

These studies show that methodologies to increase the accuracy of the WAsP model in complex terrains can give relatively good results. However, these methodologies do not remove all the errors in complex terrains. Moreover, it has been observed that significant $A E P$ errors occur even on simple terrains, where the methodologies cannot be used.

Based on these studies, several indices have been developed to better identify the effect of the terrain on the $A E P$ errors. According to these indices, a new methodology has been investigated which uses a multi-variable correlations to give more accurate results. Finally, the efficiency of this methodology will also be applied to the MS-Micro model.

Following a presentation of the measured production data available and the quality control performed on these data, the quantification of the $A E P$ errors are presented. Thereafter, the indices created to characterize the sites in terms of roughness, slopes and the position of the wind turbines relative to the meteoro- 
logical mast are introduced; this is followed by the correlations, based on the indices proposed, used to relate the $A E P$ error and the site characteristics. Finally, the results of the analysis without improvement are presented and compared to the improvements obtained due to the methodology proposed in this work. A short conclusion and recommendations for future work ends the paper.

\section{Measured Production Data}

The production data measured from five Canadian wind farms, with a global installed capacity of $350 \mathrm{MW}$, have been used to perform this study. For confidentiality reasons, the information that identifies these wind farms is not divulged.

Wind Farm I is characterized as a very simple site, with a relatively flat terrain and low roughness classes. Wind Farms II and III are complex sites with steep terrains and high roughness classes (notably forest). Finally, Wind Farms IV and $\mathrm{V}$ are simple sites with small slopes and high roughness classes.

The measured meteorological data, contour maps, roughness maps and wind farm layouts have been provided by the owners of the wind farms.

The meteorological data are ten minute averages measured at one $80 \mathrm{~m}$ meteorological (met) mast for every wind farm, while the corresponding production data cover one year of energy production for every wind farm, except for Wind Farm I where two years of meteorological and production data are available.

A quality control has been performed on the met mast measured data according to three main steps. First, the missing values and the values in the sectors that are disturbed by the tower shadow and by the wake of wind turbines in proximity to the met masts have been removed. The disturbed sector calculations have been done according to the relevant IEC standard [20]. Then, following the approach of the Wind Resource Assessment Handbook [21], data which did not satisfy one or more criteria (see Table 1) have been flagged. Finally, a visual inspection of the flagged data has been done to identify and remove time series where abnormal operations of the instruments have occurred.

A quality control has also been performed on wind turbine data. The first step in the quality control of wind turbine data is to eliminate the missing values, the values in the perturbed sectors by the wake of the wind turbines in proximity to the met mast, and the time series which are not available at the met mast. Then, the time series resulting in active power values and/or reactive power values equal to or below zero have been removed.

Since it is not common to use a met mast as far as $8 \mathrm{~km}$ from any wind turbine position when performing wind assessments, this study is limited to wind turbines located within a radius of $8 \mathrm{~km}$ from the corresponding wind farm met mast. Moreover, it has been observed that wind turbines located at a distance greater than $8 \mathrm{~km}$ have significant $A E P$ errors (see Section 6.3).

\section{Quantification of the AEP Errors}

In order to have the largest amount of unperturbed data in the various analyses, each wind turbine has been analyzed individually. Thus 197 analyses have been 
Table 1. Met mast quality control criteria for the measured data.

\begin{tabular}{|c|c|c|}
\hline Categories & Parameters & Validation Criteria \\
\hline \multirow{4}{*}{ Icing } & Temperature and, & $<2^{\circ} \mathrm{C}$ \\
\hline & Relative Humidity and, & $>80 \%$ \\
\hline & Wind direction standard deviation or & $=0^{\circ}$ \\
\hline & Mean Wind Speed & $=0 \mathrm{~m} / \mathrm{s}$ \\
\hline \multirow{5}{*}{ Range test criteria at $80 \mathrm{~m}$} & Mean wind speed & $0 \mathrm{~m} / \mathrm{s}<$ value $<25 \mathrm{~m} / \mathrm{s}$ \\
\hline & Wind speed standard deviation & $0 \mathrm{~m} / \mathrm{s}<$ value $<3 \mathrm{~m} / \mathrm{s}$ \\
\hline & Maximum gust of wind speed & $0 \mathrm{~m} / \mathrm{s}<$ value $<30 \mathrm{~m} / \mathrm{s}$ \\
\hline & Wind direction standard deviation & $1^{\circ}<$ value $<75$ \\
\hline & Max gust vs. mean wind speed & Max gust $\leq 2.5^{\star}$ Mean WS \\
\hline \multirow{3}{*}{$\begin{array}{l}\text { Relational test criteria } \\
\text { between } 80 \mathrm{~m} \text { and } 50 \mathrm{~m}\end{array}$} & $\Delta$ Mean wind speed & $\leq 2 \mathrm{~m} / \mathrm{s}$ \\
\hline & $\Delta$ Mean wind speed by day & $\leq 5 \mathrm{~m} / \mathrm{s}$ \\
\hline & $\Delta$ Mean wind direction & $\leq 20^{\circ}$ \\
\hline \multirow{2}{*}{$\begin{array}{l}\text { Relational test criteria } \\
\text { between } 80 \mathrm{~m} \text { and } 30 \mathrm{~m}\end{array}$} & $\Delta$ Mean wind speed & $\leq 4 \mathrm{~m} / \mathrm{s}$ \\
\hline & $\Delta$ Mean wind speed by day & $\leq 7.5 \mathrm{~m} / \mathrm{s}$ \\
\hline \multirow{2}{*}{ Trend test criteria } & Mean wind speed & $<5 \mathrm{~m} / \mathrm{s}$ \\
\hline & Temperature & $\leq 5^{\circ} \mathrm{C}$ \\
\hline
\end{tabular}

done for every numerical model (WAsP and Ms-Micro), which is the number of wind turbines available for this study.

To evaluate the accuracy of the analyses, the $A E P$ errors between the measured values and the estimated values from the models have been calculated for each wind turbine:

$$
A E P_{\text {error }}=\left(A E P_{\text {estimated }}-A E P_{\text {measured }}\right) / A E P_{\text {measured }}
$$

where $A E P_{\text {estimated }}$ is the $A E P$ calculated with the models and $A E P_{\text {measured }}$ is the $A E P$ measured as the output energy of the wind turbine.

Since the $A E P$ estimated by the models do not take into account the energy losses, most of these loss events (availability losses, wake losses and icing losses) have been removed from the database when calculating the $A E P_{\text {measured }}$. Also, for the same reasons, the data from wind turbines that were not operating in normal conditions (e.g. failure of a major component of the wind turbine) have been removed from the analysis. The method used to identify these wind turbines is presented in Section 5. The effects of the electric losses in the analysis have been minimized by taking the energy measurements directly at the wind turbine output. Finally, it is assumed that any other losses, which are not considered in this study, are negligible and constant for all the wind turbines analyzed.

\section{Index Classification}

In order to evaluate the effect of the different site characteristics on the $A E P$, an index classification has been developed. The indices have been divided in three categories: an index related to the position of the wind turbines relative to the met mast, an index related to the orography characteristics and an index related 
to the roughness of the terrain.

The site characteristics (orography, roughness) have been taken from the vector maps provided by the wind farm owners. Thus, it is assumed that the maps provided are representatives of the site characteristics of the wind farms studied.

The position of the wind turbines relative to the met mast has been characterized by the horizontal distance between the wind turbines and the met mast, along with the difference of height between the hub of the turbines and the top measurement height at the met mast of the wind farm.

The terrain characteristics have been evaluated on ten degree sectors over a radius corresponding to 20 times the rotor diameter $(D)$ and it includes two ruggedness parameters $(R I X)$. By definition, the $R I X$ is the fractional extent of the surrounding terrain which is steeper than a certain critical slope [16].

The first parameter is called the drop index, $R I X_{10}$, where the critical slope is $10 \%$. This index has been based on a classification of the IEC [22]. Table 2 shows the different classes of the drop index.

The second parameter is the flow separation index, which is already used by WAsP to correct the $A E P$ [23]. This method is based on the fact that a linear relationship exists between the difference of flow separation between the met mast area and the wind turbine area, and the $A E P$ error [16].

The minimum critical slope before separation of the flow has been the subject of several studies. Wood [24] summarized the critical slopes given by Grant and Mason [25] from various numerical studies of two dimensional flows. Table 3 provides a summary.

Taking into account the different values for the minimum critical slope for the separation of the flow [25], a critical slope of $40 \%$ has been used in this work.

Using the roughness classes in the European Wind Atlas [26], the land surrounding wind turbines can contain different types of roughness. However, the roughness complexity, denoted as the variation of roughness over an area of interest, cannot be properly quantified by the current roughness classes. To this

Table 2. Classes for the drop index $R I X_{10}$.

\begin{tabular}{cc}
\hline$R I X_{10}(\%)$ & Terrain class \\
\hline $0 \leq R I X_{10}<8$ & 1 \\
$8 \leq R I X_{10}<16$ & 2 \\
$16 \leq R I X_{10}<24$ & 3 \\
$24 \leq R I X_{10}$ & 4 \\
\hline
\end{tabular}

Table 3. Critical slope before separation of the flow.

\begin{tabular}{ccc}
\hline Study number & Source & Critical Slope \\
\hline I & Newley [27] & $43 \%$ \\
II & Newley [27] & $40 \%$ \\
III & Taylor et al. [28] & $31 \%$ \\
IV & Mason and King [29] & $47 \%$ \\
\hline
\end{tabular}


end, a new method of classification of the roughness has been developed to take into account the different roughness lengths and roughness variations over an area surrounding the wind turbines. This new classification has been described by the reference roughness length and the roughness complexity.

The reference roughness length is the average roughness length of the site and is obtained using the reference friction coefficient. From the equation of velocity distribution in a neutral boundary layer:

$$
U(z)=\frac{u_{*}}{\kappa}\left(\ln \frac{z}{z_{0}}\right)
$$

where $\kappa$ is the Von Karman constant, $U$ is the wind speed, $u_{*}$ is the friction velocity, $z_{0}$ is the roughness length and $z$ is the reference height. Considering the surface shear stress:

$$
\tau_{w}=\rho u_{*}^{2} \cong \frac{1}{2} \rho u(z)^{2} C_{\mathrm{d}}
$$

the friction coefficient is:

$$
C_{\mathrm{d}}=2\left(\frac{\kappa}{\ln \left(z / z_{0}\right)}\right)^{2}
$$

Currently, one of the most common hub height of wind turbines is approximately 80 meters, which is much higher than the blending height [30]. Thus, the reference height $(z)$ for the evaluation of the friction coefficient has been fixed at 80 meters.

The roughness in the vicinity, but outside of a sector, may influence the fluid inside the sector, particularly near the wind turbine of interest. Thus, the reference roughness cannot only be defined from the roughness values within the sector delimitation. The considered area is taken as a rectangle with a certain width, as shown in Figure 1, which shows the area used to calculate the roughness influence in a specific sector.

The equation of the reference friction coefficient thus becomes:

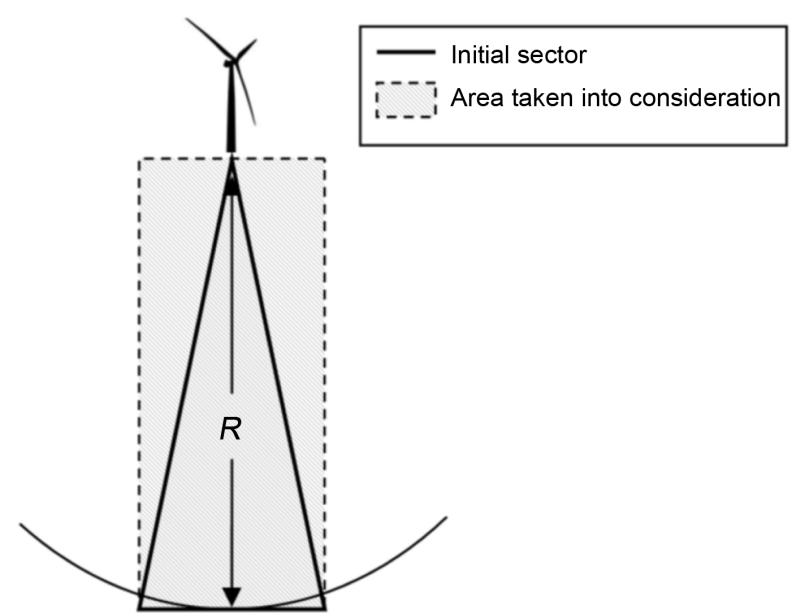

Figure 1. Area used to evaluate the roughness influence in a specific sector. 


$$
C_{\mathrm{dref}}=\sum_{n=1}^{n}\left(C_{\mathrm{d} n} * \Delta r_{n}\right) / R
$$

where $\Delta r_{n}$ is the surface length at the surface $n, R$ is the radius of the sector, $C_{\mathrm{d} n}$ is the friction coefficient at the surface $n$ and $C_{\mathrm{dref}}$ is the reference friction coefficient. Figure 2 shows the friction coefficients over the considered area.

From Equation (4), the reference roughness length is:

$$
z_{0 \text { ref }}=\exp \left(-\kappa / \sqrt{C_{d r e f}}\right) * z
$$

Then, the roughness length is converted to roughness classes according to the European Wind Atlas [26]:

For $z_{0 \text { ref }} \leq 0.03$ :

$$
\text { Class }=1.699823015+\ln \left(z_{0 r e f}\right) / \ln (150)
$$

For $z_{0 \text { ref }}>0.03$ :

$$
\text { Class }=3.912489289+\ln \left(z_{\text {oref }}\right) / \ln (3.333333333)
$$

The roughness variations have been quantified as the sum of the differences of the friction coefficients on the site:

$$
C_{R}=\sum_{n=1} \Delta C_{\mathrm{d} n}
$$

where $C_{R}$ is the roughness complexity index and $\Delta C_{\mathrm{d}}$ is defined as:

$$
\Delta C_{\mathrm{d} n}=\left|C_{\mathrm{d} n 1}-C_{\mathrm{d} n 2}\right|
$$

where $C_{\mathrm{d} n 1}$ and $C_{\mathrm{d} n 2}$ are respectively the drag coefficients before and after the roughness change $n$.

Subsequently, the roughness complexity index $C_{R}$ has been divided in classes. The development of these classes has been done as follows: First, the roughness complexity index has been calculated for each ten degree sector of the wind turbines studied. Then, the 8028 roughness complexity indices have been analyzed statistically. Table 4 shows the resulting statistical parameters. Assuming

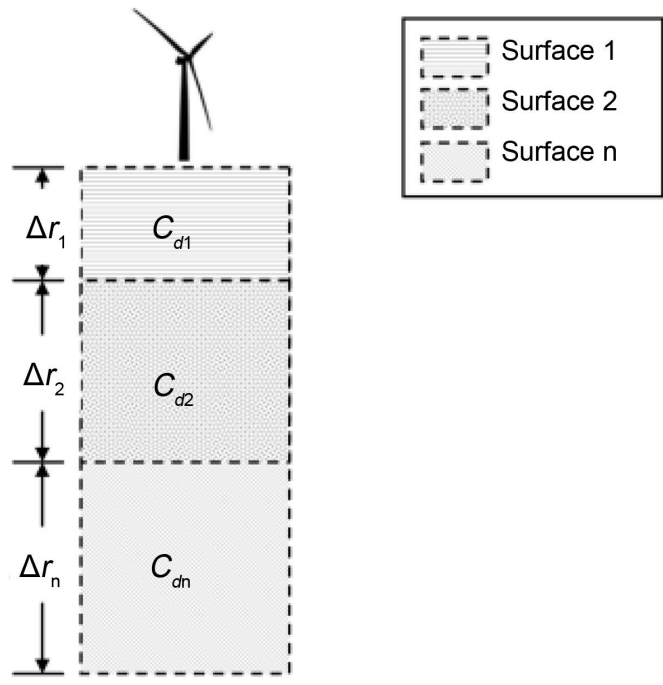

Figure 2. Friction coefficients over the considered area. 
that the $C_{R}$ indices analyzed represent the range of possible $C_{R}$ in a wind farm area, the classes have been selected by quartiles (see Table 5).

\section{Correlation Parameters of the Proposed Indices}

To be able to evaluate the effect of the different proposed indices on the $A E P$ accuracy, a multiple linear correlation, using the least square method, between the $A E P$ error and the indices has been done.

The indices have been transformed mathematically to obtain a relationship between terrain characteristics at the met mast position and at the wind turbine position. Table 6 presents these parameters. On this basis, the correlation equation proposed in this work is:

$$
\begin{aligned}
A E P_{\text {error correlated }}= & a *\left(R I X_{10 T u r b i n e}-R I X_{10 \text { Mast }}\right)+b * \ln \left(z_{\text {oref Turbine }} / z_{\text {0ref Mast }}\right)^{2} \\
& +c *\left(C_{R \text { Turbine }}-C_{R \text { Mast }}\right)+d^{*}\left(R I X_{40 \text { Turbine }}-R I X_{40 \text { Mast }}\right) \\
& +e^{*} \sqrt{l}+f * \Delta h
\end{aligned}
$$

Table 4. Statistical values of the $C_{R}$ analyzed.

\begin{tabular}{cc}
\hline Statistical parameter & Value \\
\hline Number of $C_{R}$ & 8028 \\
Average & 0.0154 \\
Standard deviation & 0.0148 \\
Minimum & 0 \\
Q1 & 0 \\
Median (Q2) & 0.0124 \\
Q3 & 0.0258 \\
Maximum & 0.0818 \\
\hline
\end{tabular}

Table 5. Classes for the roughness complexity index $C_{R}$.

\begin{tabular}{|c|c|c|}
\hline Index & Variable & Correlation parameters \\
\hline Drop & $R I X_{10}$ & $R I X_{10 T u r b i n e}-R I X_{10 \text { Mast }}$ \\
\hline Flow separation & $R I X_{40}$ & $R I X_{40 \text { Turbine }}-R I X_{40 \text { Mast }}$ \\
\hline Reference roughness & $z_{0 r e f}$ & $\ln \left(z_{\text {oref Turbine }} / z_{\text {oref Mast }}\right)^{2}$ \\
\hline Roughness complexity & $C_{R}$ & $C_{R \text { Turbine }}-C_{R \text { Mast }}$ \\
\hline Distance between the turbine and the met mast & 1 & $\sqrt{l}$ \\
\hline $\begin{array}{l}\text { Height difference between the turbine hub height and } \\
\text { met mast top measurement height }\end{array}$ & $\Delta h$ & $\Delta h$ \\
\hline
\end{tabular}

\begin{tabular}{ccc}
\hline & & $C_{R}$ Values \\
\hline Class 1 & From & To \\
Class 2 & 0 & 0 \\
Class 3 & $>0$ & 0.0124 \\
Class 4 & $>0.0124$ & 0.0258 \\
& $>0.0258$ & 0.0818 \\
\hline
\end{tabular}

Table 6. Correlation parameters. 
where $a, b, c, d, e$ and $f$ are the variables to be solved.

In order to avoid using suspicious data, usually resulting from situations which cannot be identified only by looking at the power curve, the wind turbines which have a different trend than most of the other wind turbines of the wind farms have been removed from the correlation. The methodology used to remove these wind turbines is based on the Peirce criterion [31].

The Peirce criterion is a simple method to eliminate the outlier data which are not representative of the sample of data set. The suspicious measurements are eliminated when the following condition is fulfilled:

$$
\left|x_{i}-\bar{x}\right|>\sigma P
$$

where $x_{i}$ is a measured data value, $\bar{x}$ is the mean of the data set, $\sigma$ is the "sample" standard deviation of the complete data set and $P$ is the Pierce criterion. Ross [31] denoted the Pierce criterion as the representation of the ratio of the maximum allowable deviation of a measured value from the data mean to the standard deviation, namely:

$$
P=\frac{\left|x_{i}-\bar{x}\right|_{\max }}{\sigma}
$$

\section{Results}

\subsection{Average Indices}

The average indices obtained for each wind farm are shown in Table 7. The average indices give a good overview of the site complexity. It also shows that the proposed methodology is applicable to different categories of sites.

As mentioned in Section 2, Wind Farm I is characterized by a very simple terrain with a reference roughness of Class 1, a roughness complexity of Class 2 and a drop index of Class 1. Wind Farms IV and V are characterized by simple terrains with a reference roughness of Class 1 , the roughness complexity is relatively high (Class 3 ) and the drop index is low (Class 2).

Wind Farms II and III have a relatively low reference roughness (Class 2) and a low roughness complexity (Class 2); however the drop index is high (Class 4 )

\begin{tabular}{|c|c|c|c|c|c|}
\hline Indices & Wind Farm I & Wind Farm II & Wind Farm III & Wind Farm IV & Wind Farm V \\
\hline $\begin{array}{l}\text { Reference } \\
\text { roughness }\end{array}$ & $\begin{array}{c}0.0027 \\
\text { (Class 1) }\end{array}$ & $\begin{array}{c}0.6899 \\
\text { (Class 2) }\end{array}$ & $\begin{array}{c}0.6366 \\
\text { (Class 2) }\end{array}$ & $\begin{array}{c}0.1474 \\
\text { (Class 1) }\end{array}$ & $\begin{array}{c}0.1521 \\
\text { (Class 1) }\end{array}$ \\
\hline $\begin{array}{l}\text { Roughness } \\
\text { complexity }\end{array}$ & $\begin{array}{c}0.0011 \\
\text { (Class 2) }\end{array}$ & $\begin{array}{c}0.0051 \\
\text { (Class 2) }\end{array}$ & $\begin{array}{c}0.0043 \\
\text { (Class 2) }\end{array}$ & $\begin{array}{c}0.0104 \\
\text { (Class 3) }\end{array}$ & $\begin{array}{c}0.0111 \\
\text { (Class 3) }\end{array}$ \\
\hline Drop & $\begin{array}{c}0 \\
\text { (Class 1) }\end{array}$ & $\begin{array}{c}36 \\
\text { (Class 4) }\end{array}$ & $\begin{array}{c}45 \\
\text { (Class } 4)\end{array}$ & $\begin{array}{c}3 \\
\text { (Class 2) }\end{array}$ & $\begin{array}{c}2 \\
\text { (Class 2) }\end{array}$ \\
\hline $\begin{array}{c}\text { Flow } \\
\text { separation }\end{array}$ & 0 & 4 & 2 & 0 & 0 \\
\hline $\begin{array}{c}\text { Height } \\
\text { difference }(\mathrm{m})\end{array}$ & -7 & -2 & -3 & 29 & 24 \\
\hline Distance (m) & 1529 & 4608 & 3753 & 3095 & 3686 \\
\hline
\end{tabular}

Table 7. Average indices for each wind farm. 
and flow separation is observed in these area. Thus, these wind farms are considered as complex terrains.

\subsection{Annual Energy Production Errors}

Figure 3 shows the average $A E P$ errors and the average absolute $A E P$ errors for the wind turbines, along with the global $A E P$ errors for the wind farms. From Figure 3, it can be seen that for Wind Farm I, WAsP underestimates the $A E P$ while MS-Micro gives better results but nonetheless overestimates the $A E P$.

Regarding the wind farms located in complex sites, both models underestimate the $A E P$ of Wind Farm II, with an $A E P$ error being relatively high by exceeding $10 \%$. However, WAsP gives the best results for this wind farm. For its part, Wind Farm III is characterized by the largest $A E P$ errors, where the models overestimate the $A E P$ of Wind Farm III, with WAsP having the smallest $A E P$ errors.

For the wind farms located in simple sites, the $A E P$ of Wind Farm IV is overestimated by WAsP and MS-Micro; however, the $A E P$ errors are relatively low, which is expected for a simple terrain wind farm. For this wind farm, MS-Micro gives the best results, albeit by a relatively small margin.
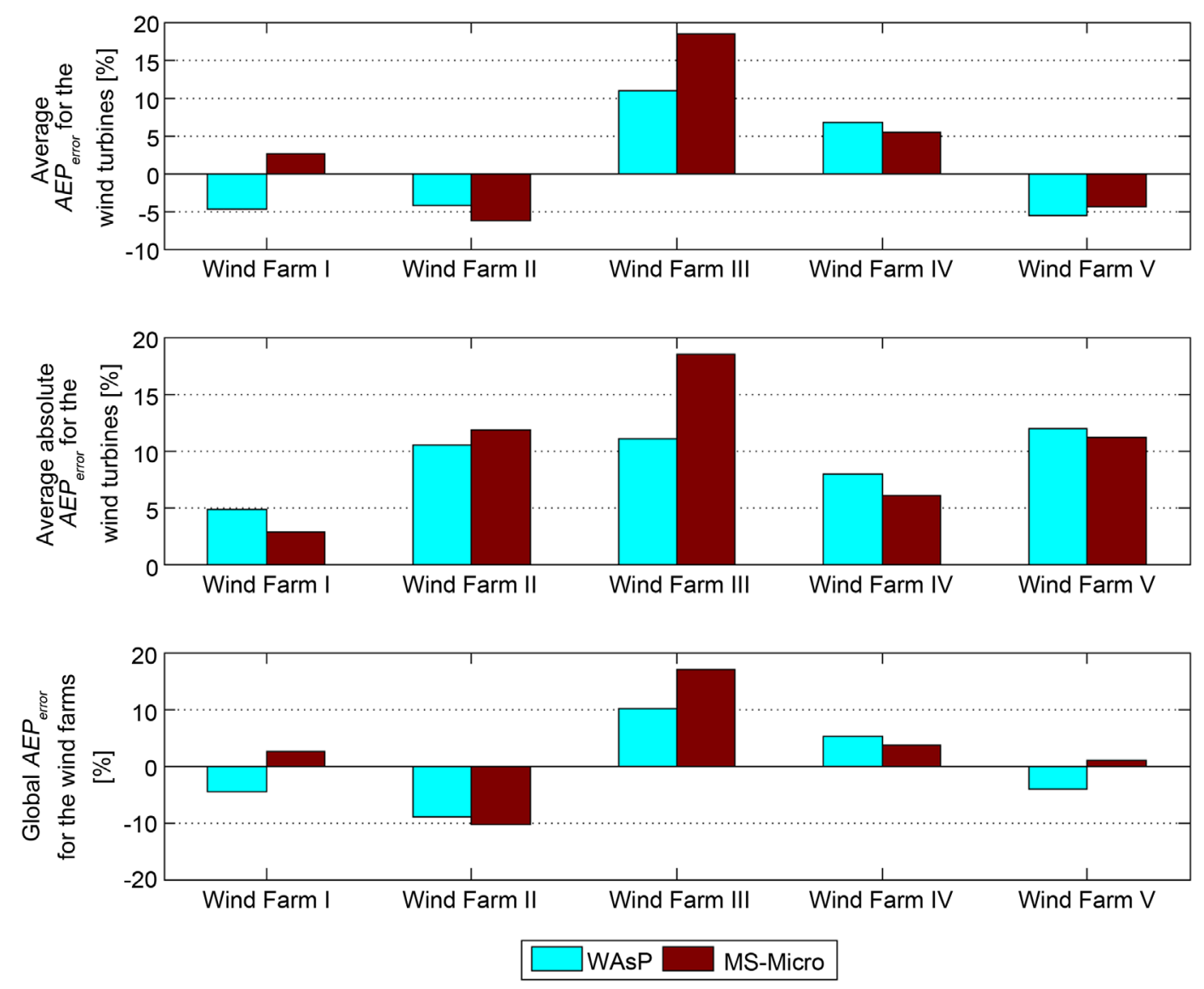

Figure 3. Average $A E P$ errors between the measured values and the estimated values for both numerical models. 
Finally, Wind Farm $\mathrm{V}$ has high average absolute $A E P$ errors for the wind turbines, and these $A E P$ errors are in the same order as the $A E P$ errors for the wind farms in complex terrains. This result suggests that errors, or a component of the errors, are induced by characteristics that are not related to the terrain. For this wind farm, MS-Micro gives the best results.

As expected, these results show that the largest $A E P$ errors occur for wind farms in complex terrains. Furthermore, it appears from these results, and for the wind farms studied, that MS-Micro gives better results than WAsP for wind farms characterized by simple sites, while, in contrast, WAsP gives better results for wind farms characterized by complex sites. This is only an observation since the numerous calculations done were not clearly indicating any physical reason for this behavior.

\subsection{Example of Correlation Results}

This section shows an example of detailed correlation results. For this purpose, Wind Farm III has been analyzed with MS-Micro; Table 8 shows the initial AEP errors.

As expected and as shown in Figure 4, especially in complex terrains, the distance of the wind turbines from the met mast has a significant influence on the $A E P_{\text {error }}$.

It has been observed that above $8 \mathrm{~km}$, the influence of the distance on the $A E P_{\text {error }}$ is so high that the correlation with the other parameters, enumerated in

Table 8. Initial $A E P$ errors-wind farm III-MS-Micro model.

\begin{tabular}{ccc}
\hline & Turbines available & Turbines $\leq 8 \mathrm{~km}$ \\
\hline Number & 30 & 26 \\
$A E P$ error - average by turbines & $18.5 \%$ & $15.3 \%$ \\
$A E P$ error-average absolute by turbine & $18.5 \%$ & $15.3 \%$ \\
$A E$ error-wind farm & $17.1 \%$ & $14.4 \%$ \\
\hline
\end{tabular}

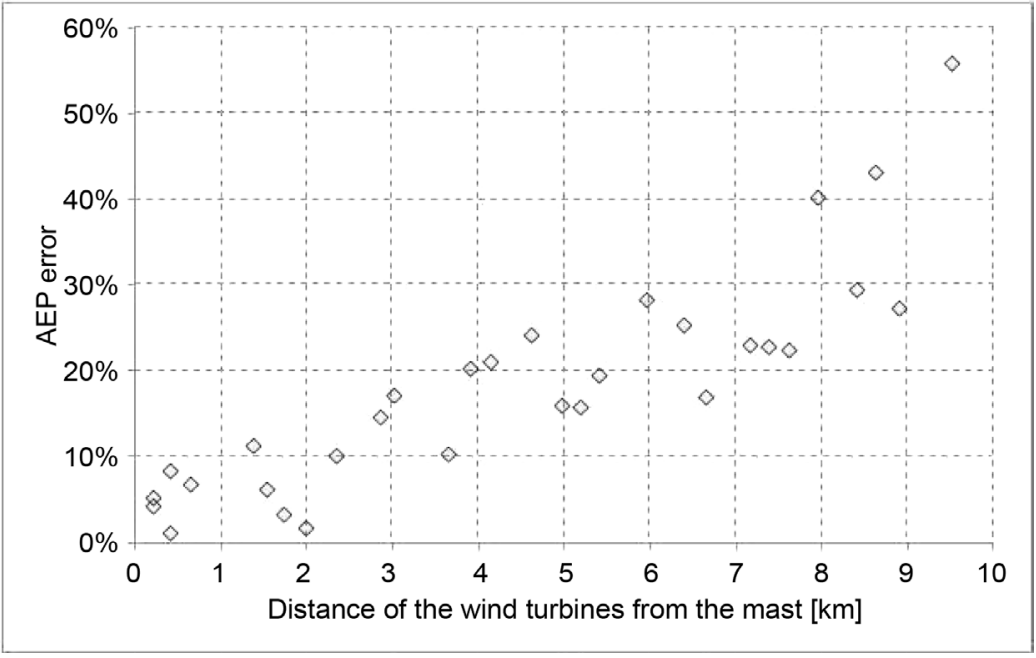

Figure 4. Influence of the distance on the $A E P_{\text {error }}$ - wind farm III-MS-Micro model. 
Table 6, is not representative. According to this observation, and in order to evaluate the influence of all the parameters, the wind turbines located at a distance above $8 \mathrm{~km}$ were removed from the analyses.

Figure 5 presents the correlation curve obtained for Wind Farm III using the parameters of Equation (11). The values of the parameters are given in Equation (14).

$$
\begin{aligned}
A E P_{\text {error correlated }}= & 0.0014\left(R I X_{10 T u r b i n e}-R I X_{10 \text { Mast }}\right)-0.0358 \ln \left(z_{\text {oref Turbine }} / z_{\text {oref Mast }}\right)^{2} \\
& +0.4812\left(C_{R \text { Turbine }}-C_{R \text { Mast }}\right)-0.0001\left(R I X_{40 \text { Turbine }}-R I X_{40 \text { Mast }}\right) \\
& +0.0025 \sqrt{l}-0.0012 \Delta h
\end{aligned}
$$

This correlation has an $R^{2}$ of $96.8 \%$ and a mean absolute error of $2.2 \%$. The $A E P$ errors corrected and the improvement of this methodology are presented in Table 9.

Equation (15) shows the formulation for the $A E P$ errors corrected, namely:

$$
A E P_{\text {error corrected }}=A E P_{\text {error }}-A E P_{\text {error correlated }}
$$

where $A E P_{\text {error corrected }}$ is the $A E P_{\text {error }}$ calculated with the correlation equation.

Then, Equation (16) shows the improvement calculation:

$$
\text { Improvement }=\frac{\left|A E P_{\text {error }}\right|-\left|A E P_{\text {error corrected }}\right|}{\left|A E P_{\text {error }}\right|}
$$

\subsection{Overall Results}

Figure 6 and Figure 7 show, for each wind farm, the $A E P$ error corrected and

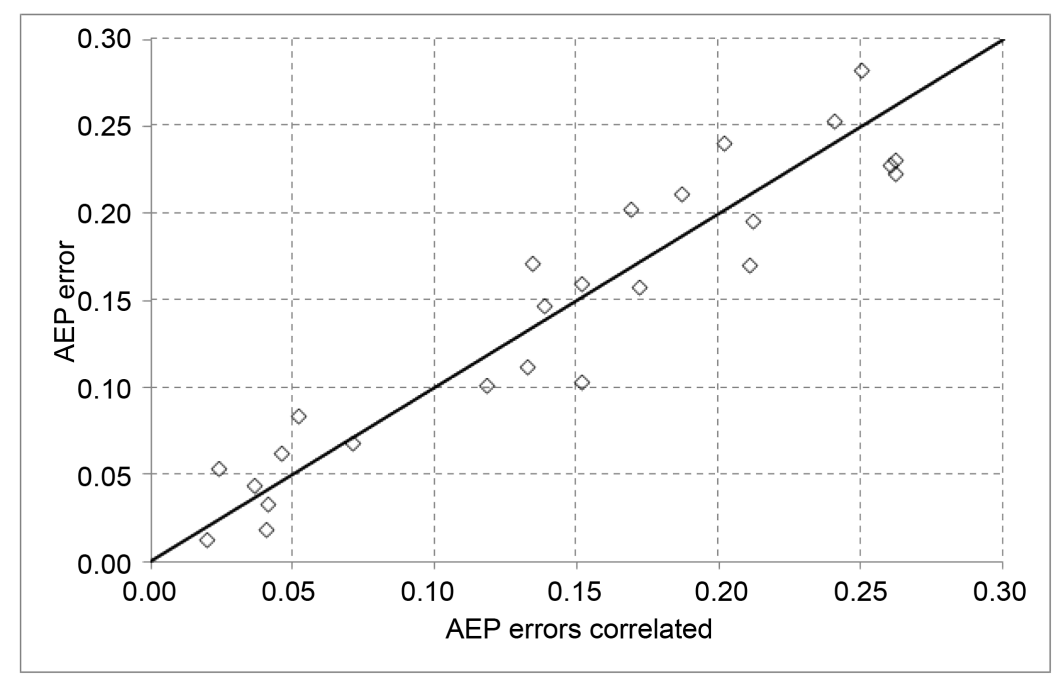

Figure 5. Correlation results-wind farm III-MS-Micro model.

Table 9. Correction results-wind farm III-MS-Micro model.

\begin{tabular}{cccc}
\hline & $A E P$ errors & AEP errors corrected & Improvement \\
\hline Average by turbines & $15.3 \%$ & $-0.8 \%$ & $94.9 \%$ \\
Average absolute by turbine & $15.3 \%$ & $2.7 \%$ & $82.2 \%$ \\
Wind farm & $14.4 \%$ & $-1.9 \%$ & $87.1 \%$ \\
\hline
\end{tabular}




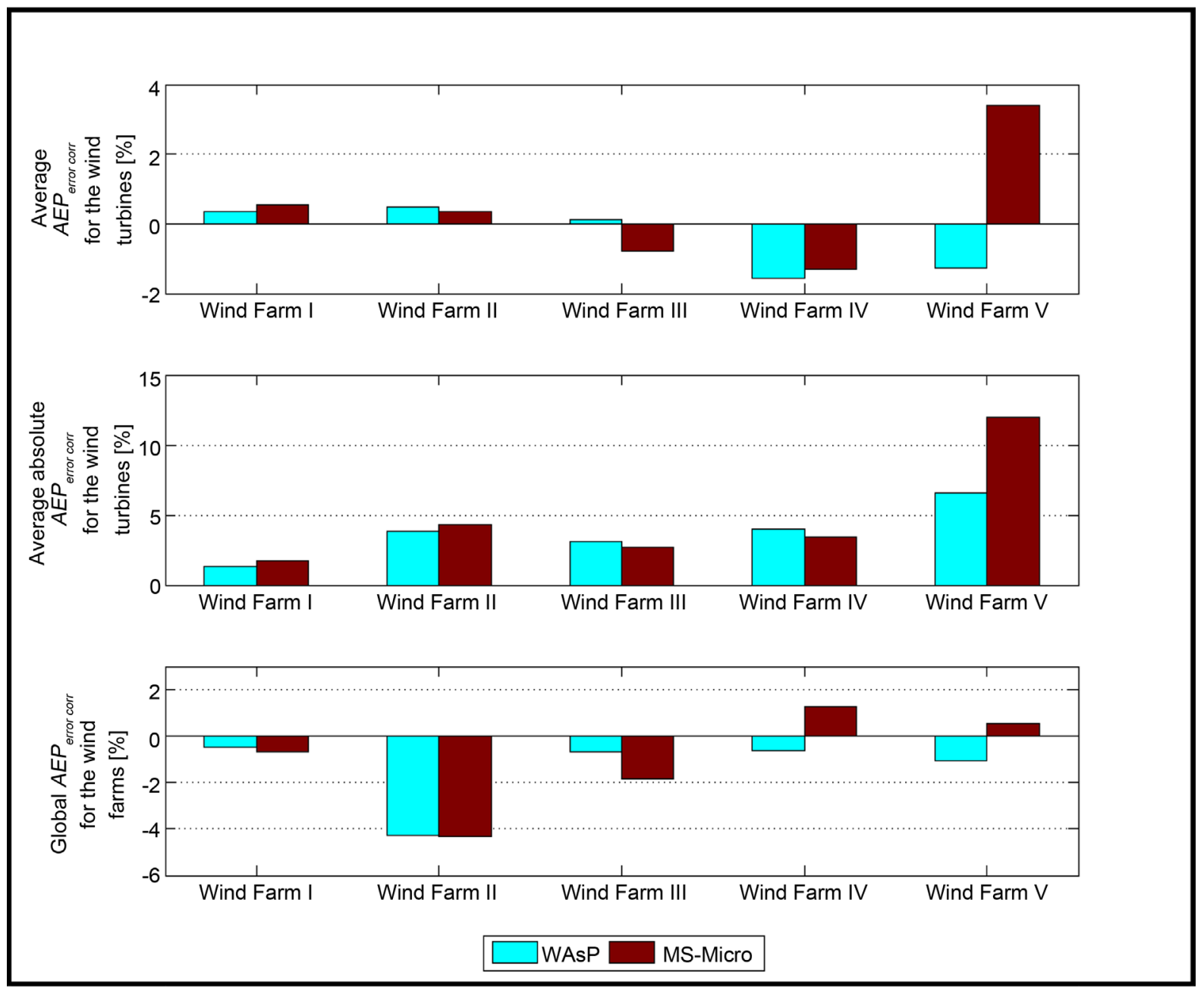

Figure 6. $A E P$ errors corrected for each wind farm.

the improvement obtained in predicting the $A E P$ using the proposed methodology, respectively.

The $A E P$ errors for the wind farms, initially up to $17 \%$, were reduced to values below $5 \%$ when using the methodology based on the proposed indices. Similar observations are applicable for the $A E P$ errors and the absolute average $A E P$ errors for the wind turbines, where the corrected errors are respectively below $2 \%$ and 5\%, with the exception of Wind Farm V.

It has been seen that Wind Farm $\mathrm{V}$ has relatively high $A E P$ errors for a simple terrain wind farm. This observation shows that the $A E P$ errors could be influenced by other parameters that this study does not take into account.

Nevertheless, the methodology proposed shows a significant improvement of the $A E P$ errors, up to $98 \%$ for Wind Farm III. The average improvement is $83 \%$ for the average $A E P$ errors for the wind turbines and $74 \%$ for the average $A E P$ error of the wind farms.

\section{Conclusion and Future Work}

A methodology has been developed to reduce the errors in the prediction of the 


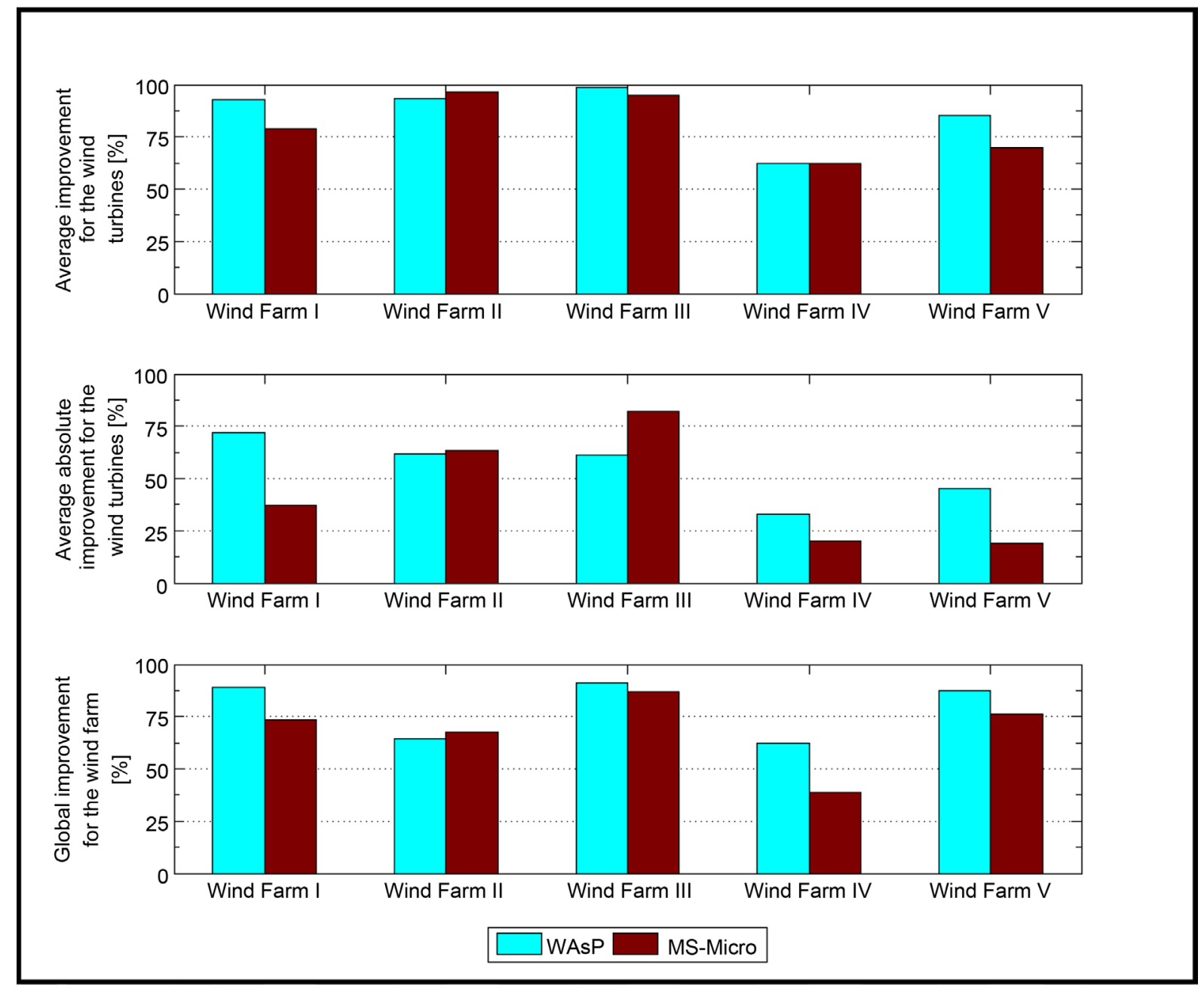

Figure 7. $A E P$ error improvement for each wind farm.

annual energy production $(A E P)$ of wind farm power production. Various indices have been proposed to better identify the characteristics of wind farm sites. Notably, a roughness classification has been developed, which includes a reference roughness index and a roughness complexity index.

Moreover, a drop index, a flow separation index, the horizontal and vertical distance between the met mast and the wind turbines have also been proposed and used. These indices have been transformed mathematically to obtain relationships between terrain characteristics at the met mast locations and the wind turbine locations. Then, multiple linear correlations have been performed in order to develop equations of the predicted $A E P$ error as a function of these indices.

The efficiency of this methodology has been proven by reducing the $A E P$ errors by an average of $83 \%$ for the wind turbines and by an average of $74 \%$ for the wind farms.

The methodology could also be applied to the wind speed instead of the energy production. If the methodology is validated with the wind speed as the reference variable, it would be possible to use this methodology in the wind condition assessment studies before the implantation of wind turbines. Thus, the errors on 
the wind condition at the wind turbine locations and on the energy production assessment could be considerably reduced.

Some additional analysis could also be done to improve the classifications; notably, the variation of the radius of analysis, defined initially by $20 \mathrm{D}$, could be optimized.

Moreover, the terrain and the roughness indices could be weighted according to their distance from the turbine, while other indices could be included in the correlation (e.g. flow stability, turbulence, etc.).

\section{Acknowledgements}

This work has been done within the Wind Energy Strategic Network (WESNet), a Canadian research network supported by the Natural Sciences and Engineering Research Council (NSERC) of Canada and by industry. The authors are also very grateful to the PEI Energy Corporation and an undisclosed Canadian wind energy independent power producer for providing production data of their wind farms.

\section{References}

[1] CanWEA, Canadian Wind Energy Association (2016) Installed Capacity. http://canwea.ca/wind-energy/installed-capacity/

[2] ecoERP (2016) ecoEnergy for Renewable Power, Natural Resources Canada. www.nrcan.gc.ca/ecoaction/14145

[3] Royer, J. (2011) Getting the Facts on Wind Energy in Canada: Notable Information Derived from the Federal Wind Programs. CanWEA 2011, Vancouver, Canada.

[4] Carvalho, D., Rocha, A., Santos, C.S. and Pereira, R. (2013) Wind Resource Modeling in Complex Terrain using Different Mesoscale-Microscale Coupling Techniques. Applied Energy, 108, 493-504. https://doi.org/10.1016/j.apenergy.2013.03.074

[5] Jung, S., Vanli, O.A. and Kwon, S.D. (2013) Wind Energy Potential Assessment Considering the Uncertainties Due to Limited Data. Applied Energy, 102, 1492 1503. https://doi.org/10.1016/j.apenergy.2012.09.011

[6] Rehman, S., Mahbub, A.M., Meyer, J.P. and Al-Hadhrami, L.M. (2012) Wind Speed Characteristics and Resource Assessment Using Weibull Parameters. International Journal of Green Energy, 9, 800-814. https://doi.org/10.1080/15435075.2011.641700

[7] Rehman, S., Aftab, A. and Al-Hadhrami, L.M. (2011) Development and Economic Assessment of a Grid Connected 20 MW Installed Capacity Wind Farm. Renewable and Sustainable Energy Reviews, 15, 833-838. https://doi.org/10.1016/i.rser.2010.09.005

[8] Touani, I., Yu, W., Gagnon, Y. and Masson, C. (2013) Development of a Wind to Power Model for Wind Farm Power Production Forecasting. Wind Engineering, 37, 347-368. https://doi.org/10.1260/0309-524X.37.4.347

[9] Kwon, S.-D. (2010) Uncertainty Analysis of Wind Energy Potential Assessment. Applied Energy, 87, 856-865. https://doi.org/10.1016/j.apenergy.2009.08.038

[10] Risø National Laboratory, WAsP 10 (2010).

[11] Zephyr North (2010) MS-Micro Version 3.

[12] Jackson, P.S. and Hunt, J.C.R. (1975) Turbulent Wind Flow over a Low Hill. Quar- 
terly Journal of the Royal Meteorological Society, 101, 929-955. https://doi.org/10.1002/qj.49710143015

[13] Bowen, A.J. and Mortensen, N.G. (1996) Exploring the Limits of WAsP the Wind Atlas Analysis and Application Program. Proceedings of 1996 European Union Wind Energy Conference, Göteborg, 20-24 May 1996, 584-587.

[14] Bowen, A.J. and Mortensen, N.G. (2004) WAsP Prediction Errors Due to Site Orography. Risø National Laboratory, Roskilde, 65.

[15] Rathmann, O., Mortensen, N.G., Landberg, L. and Bowen, A. (1997) Assessing the Accuracy of WAsP in Non-Simple Terrain. Proceedings of BWEA Conference, Exeter, 25-27 September 1996, 413-418.

[16] Mortensen, N.G., Bowen, A.J. and Antoniou, I. (2006) Improving WAsP Predictions in (too) Complex Terrain. Proceedings of 2006 European Wind Energy Conference and Exhibition, Athens, 27 February-2 March 2006, 175-183.

[17] Berge, E., Nyhammer, F., Tallhaug, L. and Jacobsen, O. (2006) An Evaluation of the WAsP Model at a Coastal Mountainous Site in Norway. Wind Energy, 9, 131-140. https://doi.org/10.1002/we.191

[18] Feng, S.-L., Wang, W.-S., Liu, C. and Dai, H.-Z. (2009) Study on the Error Evaluation Method of Calculated Energy Production by WAsP When the Terrain Gets Complex. International Conference on Sustainable Power Generation and Supply, Nanjing, 6-7 April 2009, 1-4. https://doi.org/10.1109/SUPERGEN.2009.5348148

[19] Jimenez, B., Durante, F., Lange, B., Kreutzer, T. and Tambke, J. (2007) Offshore Wind Resource Assessment with WAsP and MM5: Comparative Study for the German Bight. Wind Energy, 10, 121-134. https://doi.org/10.1002/we.212

[20] IEC (2005) Power Performance Measurements of Electricity Producing Wind Turbines. 61400-12-1, IEC, Geneva.

[21] AWS SI (1997) Wind Resource Assessment Handbook. National Renewable Energy Laboratory, Golden.

[22] IEC (2013) Power Performance of Electricity Producing Wind Turbines Based on Nacelle Anemometry. 61400-12-2, IEC, Geneva.

[23] Mortensen, N.G., Heathfield, D.N., Myllerup, L., Landberg, L. and Rathmann, O. (2007) Getting Started with WAsP 9. Riso National Laboratory, Roskilde.

[24] Wood, N. (1995) The Onset of Separation in Neutral, Turbulent Flow over Hills. Boundary-Layer Meteorology, 76, 137-164. https://doi.org/10.1007/BF00710894

[25] Grant, A.L.M. and Mason, P.J. (1990) Observations of Boundary-Layer Structure over Complex Terrain. Quarterly Journal of the Royal Meteorological Society, 116, 159-186. https://doi.org/10.1002/qj.49711649107

[26] Troen, I. and Petersen, E.L. (1989) European Wind Atlas. Risø National Laboratory, Roskilde.

[27] Newley, T.J. (1985) Turbulent Airflow over Hills. Cambridge University, Cambridge.

[28] Taylor, P.A., Gent, P.R. and Keen, J.M. (1976) Some Numerical Solutions for Turbulent Boundary Layer Flow above Fixed Rough, Wavy Surfaces. Geophysical Journal International, 44, 177-201. https://doi.org/10.1111/j.1365-246X.1976.tb00281.x

[29] Mason, P.J. and King, J.C. (1984) Atmospheric Flow over a Succession of Nearly Two-Dimensional Ridges and Valleys. Quarterly Journal of the Royal Meteorological Society, 110, 821-845. https://doi.org/10.1002/qj.49711046604

[30] Mason, P.J. (1988) The Formation of a Really-Averaged Roughness Lengths. Quarterly Journal of the Royal Meteorological Society, 114, 399-420. 
https://doi.org/10.1002/qj.49711448007

[31] Ross, S.M. (2003) Peirce's Criterion for the Elimination of Suspect Experimental Data. Journal of Engineering Technology, 20, 38-41. 


\section{Nomenclature}

\begin{tabular}{|c|c|c|}
\hline a & \multicolumn{2}{|l|}{ Correlation coefficient (see Equation (11)) } \\
\hline$b$ & \multicolumn{2}{|l|}{ Correlation coefficient (see Equation (11)) } \\
\hline$c$ & \multicolumn{2}{|l|}{ Correlation coefficient (see Equation (11)) } \\
\hline$d$ & \multicolumn{2}{|l|}{ Correlation coefficient (see Equation (11)) } \\
\hline$e$ & \multicolumn{2}{|l|}{ Correlation coefficient (see Equation (11)) } \\
\hline$t$ & \multicolumn{2}{|l|}{ Correlation coefficient (see Equation (11)) } \\
\hline$\kappa$ & \multicolumn{2}{|l|}{ von Karman constant } \\
\hline 1 & \multicolumn{2}{|l|}{ Distance between the turbine and the mast } \\
\hline$\sigma$ & \multicolumn{2}{|l|}{ Sample standard deviation } \\
\hline$\rho$ & \multicolumn{2}{|l|}{ Air density } \\
\hline$\tau_{w}$ & \multicolumn{2}{|l|}{ Surface shear stress } \\
\hline$u^{*}$ & \multicolumn{2}{|l|}{ Friction velocity } \\
\hline$x$ & \multicolumn{2}{|l|}{ Data value } \\
\hline$z$ & \multicolumn{2}{|l|}{ Elevation with respect to the ground } \\
\hline$z_{o}$ & \multicolumn{2}{|l|}{ Roughness length } \\
\hline$A E P$ & \multicolumn{2}{|l|}{ Annual energy production } \\
\hline$C_{\mathrm{d}}$ & \multicolumn{2}{|l|}{ Friction coefficient } \\
\hline Class & \multicolumn{2}{|l|}{ Roughness class } \\
\hline$C_{R}$ & \multicolumn{2}{|l|}{ Roughness complexity } \\
\hline \multicolumn{3}{|c|}{ Improvement } \\
\hline$P$ & \multicolumn{2}{|l|}{ Pierce criterion } \\
\hline$R$ & Radius of the sector & {$[\mathrm{m}]$} \\
\hline$R I X$ & \multicolumn{2}{|l|}{ Ruggedness parameter } \\
\hline$U$ & Wind speed & {$[\mathrm{m} / \mathrm{s}]$} \\
\hline$\Delta C_{\mathrm{d}}$ & \multicolumn{2}{|l|}{ Variation in friction coefficient } \\
\hline$\Delta h$ & Difference in turbine and mast heights & {$[\mathrm{m}]$} \\
\hline$\Delta r$ & Surface length & {$[\mathrm{m}]$} \\
\hline
\end{tabular}

\section{Subscript}

\begin{tabular}{|c|c|}
\hline corrected & related to corrected values \\
\hline correlated & related to the correlated values \\
\hline error & related to the relative error \\
\hline estimated & related to the estimation values \\
\hline$i$ & related to a given value \\
\hline measured & related to the measurement values \\
\hline$n$ & related to the $n$ surface \\
\hline ref & related to reference value \\
\hline Mast & related to the mast position \\
\hline Turbine & related to the turbine position \\
\hline 1 & related to the upstream roughness change \\
\hline 2 & related to the downstream roughness change \\
\hline 10 & computed values using $10 \%$ slope \\
\hline 40 & computed values using $40 \%$ slope \\
\hline
\end{tabular}




\section{Superscript}

averaging operator

Submit or recommend next manuscript to SCIRP and we will provide best service for you:

Accepting pre-submission inquiries through Email, Facebook, LinkedIn, Twitter, etc. A wide selection of journals (inclusive of 9 subjects, more than 200 journals)

Providing 24-hour high-quality service

User-friendly online submission system

Fair and swift peer-review system

Efficient typesetting and proofreading procedure

Display of the result of downloads and visits, as well as the number of cited articles

Maximum dissemination of your research work

Submit your manuscript at: http://papersubmission.scirp.org/

Or contact jfcmv@scirp.org 